\title{
Bone Transport in Tibial Gap Non-Union-A Series of 25 Cases
}

\author{
Manish Kiran $^{1 *}$, Rabi Jee ${ }^{2}$ \\ ${ }^{1}$ Ninewells hospital, Dundee, UK; ${ }^{2}$ SCB Medical College, Cuttack, India. \\ Email: ${ }^{*}$ drmanishkiran@gmail.com \\ Received July $9^{\text {th }}, 2012$; revised August $9^{\text {th }}, 2012$; accepted October $8^{\text {th }}, 2012$
}

\begin{abstract}
Gap non-union of the tibia is frequently associated with deformity, infection and shortening. Ilizarov's method of bone transport was used in the management of twenty-five cases of gap non-union of the tibia. The mean bone gap was 6.53 $\mathrm{cm}$ (range 4 to $12 \mathrm{~cm}$ ). Union was achieved in all cases within a mean period of 11.12 months. The mean time taken for union, per centimeter of bone gap was found to be $1.7 \mathrm{months} / \mathrm{cm}$. Pin tract infection was the commonest complication, seen in 9 cases (36\%). The other complications encountered were neuropraxia $(n=3)$ deviation of the transported bone segment $(n=7)$, buckling of skin at the advancing side of bone $(n=4)$, traumatic corticotomy $(n=3)$, incomplete corticotomy $(n=1)$, equinus deformity $(n=4)$, knee stiffness $(n=4)$ and curling of toes $(n=4)$. The bone healing results were excellent in $92 \%$ of cases and good in $8 \%$ of cases. The functional results were excellent in $84 \%$ of cases, good in $12 \%$ and fair in $4 \%$ of cases. Thus bone transport by Ilizarov's method manages the bone loss and the associated conditions with good bone healing and functional results.
\end{abstract}

Keywords: Tibial Gap Non-Union; Bone Transport; Ilizarov's Method

\section{Introduction}

The tibia is one of the most commonly fractured long bones [1]. Open fractures are more common in the tibia than in any other major long bone [1]. High-energy fractures may be associated with bone loss, compartment syndrome and neurovascular injury. Improvements in medical science have shifted the treatment philosophy of such fractures from amputation towards limb salvaging procedures. The result of this paradigm shift is an increase in non-union associated with other complications like bone loss resulting in a gap, shortening, infection and deformity. The treatment of such complicated nonunions presents a formidable challenge to orthopaedic surgeons. The concept of distraction osteogenesis has been used in various situations like limb lengthening, bone transport and deformity correction. Bone transport using this principle enables the management of tibial bone loss and all its associated problems. The aim of this study was to assess the outcome of management of gap non-union of the tibia by bone transport using Ilizarov's method.

\section{Materials and Method}

Twenty-five cases of gap non-union of the tibia were in-

"Corresponding author. cluded in the study. The mean age of the patients was 34.54 years (range 21 to 54 years). There were 18 males and 7 females. The mode of initial injury was a road traffic accident in 21 cases and fall from height in 4 cases. The mean duration since fracture was 10.58 months. All the fractures were open. There were twelve cases of grade $3 \mathrm{~B}$, six cases of grade $3 \mathrm{~A}$, five cases of grade 1 and two cases of grade 2, according to Gustillo-Anderson's classification of open fractures. The modality of initial management was an external fixator in eighteen cases, intramedullary nailing in five cases and manipulation and above knee POP cast with a window, in two cases. The type of non-union at the time of application of the ring fixator was B3 in fifteen cases and B1 in ten cases according to Paley's classification of non-union of long bones [2,3]. Infection was quiescent in 14 cases and draining in 11 cases. The mean bone gap was $6.53 \mathrm{~cm}$ (range 4 to $12 \mathrm{~cm}$ ). The cases had undergone a mean of 1.4 surgeries ( 1 - 4 surgeries) before bone transport. The cases were carefully assessed both clinically and radiologically preoperatively. The associated problems like infection, deformity and shortening were documented. Fibulectomy was done at a level different from the proposed corticotomy and non-union sites. Debridement was done in case of persistent infection and the material sent for culture and sensitivity tests. Ring fixator using the 
principles of Ilizarov was applied using a free hand technique in all cases. The wires were applied in the safe zones in each segment. Intra operative correction of deformity was attempted and if not possible, hinges were applied at the appropriate level to facilitate gradual post operative correction. Corticotomy was done in all cases. The pin sites were dressed with povidone iodine soaked gauze pieces and a rubber stopper was applied. The corticotomy, fibulectomy and debridement wounds were dressed using sterile gauze.

Post-operatively, the limb was elevated to prevent oedema. Distal neurovascular status was constantly monitored. Six doses of intravenous Cefuroxime were prescribed. This was followed by oral/ intra-venous antibiotics based on the culture and sensitivity for a period of three weeks. Pin tract dressing using spirit or povidone iodine was taught and the patients were encouraged to do it themselves.

A latent period of seven days was given before starting distraction. After the latent period, distraction at the corticotomy site was started at the rate of $1 \mathrm{~mm}$ /day i.e. 0.25 $\mathrm{mm}$ every 6 hours. The patient was instructed to walk with gradually increasing weight bearing using two crutches. A foot orthosis was attached to the frame. The assistance was gradually tapered down to one crutch and finally to full weight bearing without any assistance. Physiotherapy of the knee and ankle were instituted. Based on the appearance of regenerate on the follow up roentgenograms, the speed of distraction was adjusted. After docking, the rate of compression was slowed down to $0.25 \mathrm{~mm} / 3$ days [4]. Bone grafting was not done in any case.

Union was assessed based on clinical and radiological criteria. The clinical criteria used were absence of pain and tenderness at the docking site and absence of abnormal mobility assessed by disconnecting the rings on either side of the docking site and moving the bone segments. The radiological criteria used were consolidation of regenerate in atleast 3 of the 4 cortices and appearance of trabecular continuity. After the removal of the frame a patellar tendon bearing cast was applied for a period of three weeks with full weight bearing. After removal of the cast the patient was allowed to walk without assistance.

The final outcome of management was assessed based on bone healing and functional results. The bone healing was graded, according to Paley's criteria [2], as excellent when union was achieved along with absence of infection, a deformity $<7^{\circ}$ and limb length discrepancy $<2.5$ $\mathrm{cm}$. It was graded as good when there was union along with any two of the other three criteria and fair when only one of the three criteria was fulfilled along with union. Nonunion along with a persistent or recurrent infection was considered a poor result.
The functional results were graded, as per ASAMI criteria, as excellent when the patient was active, without a limp, with minimum stiffness $\left(<15^{\circ}\right.$ knee flexion deformity $/ 15^{\circ}$ loss of dorsiflexion of ankle), no reflex sympathetic dystrophy (RSD) and had no pain. It was graded as good when the patient was active with one or two of the following: limp, stiffness, RSD or significant pain and fair when three or all of the following: limp, stiffness, RSD or significant pain were present. A poor result was when the patient was inactive and unemployed or was unable to do activities of daily living due to the injury. An amputation was considered a failure. The patients were followed up for a period of 24 to 41 months (mean 29 months).

\section{Results}

Union was achieved in all cases within a mean period of 11.12 months (range 6.5 to 14.5 months). The mean time taken for union, per centimeter of bone gap was found to be 1.7 months $/ \mathrm{cm}$. Pin tract infection was seen in nine cases $(36 \%)$, all of them being grade 1 infection, according to Paley's classification. Transient neuropraxia was observed in three cases (12\%), which resolved completely within 3 months. Deviation of the transported bone segment was seen in seven cases $(28 \%)$. Buckling of skin at the advancing side of bone was seen in four cases $(16 \%)$. Corticotomy related complications were seen in $16 \%$ of cases, three cases of traumatic corticotomy and one case of incomplete corticotomy. Equinus deformity occurred in four cases $(16 \%)$. Knee stiffness was present in four cases. Curling of toes occurred in four cases $(16 \%)$. Pain was persistent in one case. There was no case with persistent infection, residual limb length discrepancy $>2.5 \mathrm{~cm}$ or refracture after fixator removal. The bone healing results were excellent in $92 \%$ of cases and good in $8 \%$ of cases. The functional results were excellent in $84 \%$ of cases, good in $12 \%$ and fair in $4 \%$ of cases. Table 1 shows the results of all cases. The result of one of the cases is shown in Figures 1 to 6.

\section{Discussion}

The difficulty in the management of non-union of long bones is compounded by the presence of bone loss, shortening, infection and deformity. The bone gap may be spontaneous due to bone loss during the initial injury or iatrogenically produced after debridement for osteomyelitis occurring after the initial management. Tibial bone loss may occur after high velocity road traffic accidents. It may also be seen in gunshot injuries [5,6]. Aseptic non-union without gap has been treated with refixation with various implants like plates and screws and intramedullary nails with bone grafting. The presence of a gap excludes the use of these modalities. Bone trans- 
Table 1. Clinical details of the patients.

\begin{tabular}{|c|c|c|c|c|c|c|c|c|c|c|c|c|c|c|c|c|}
\hline S. No & Duration (months) & Grade & Initial man & Classify & Inf & Gap $(\mathrm{cm})$ & UT & PI & $\mathrm{D}$ & LLD & Limp & Pain & $\mathrm{EQ} / \mathrm{FF}$ & RSD & $\mathrm{ADL}$ & Pin inf \\
\hline 1 & 9.5 & $3 \mathrm{~B}$ & $\mathrm{EF}$ & B3 & A & 7.4 & 11.5 & $\mathrm{~N}$ & $4^{\circ}$ & $\mathrm{Y}$ & $\mathrm{N}$ & $\mathrm{N}$ & $\mathrm{N}$ & $\mathrm{N}$ & $\mathrm{Y}$ & $\mathrm{Y}$ \\
\hline 2 & 10 & $3 \mathrm{~B}$ & $\mathrm{EF}$ & B3 & A & 9.5 & 13.5 & $\mathrm{~N}$ & $4^{\circ}$ & $\mathrm{Y}$ & $\mathrm{Y}$ & $\mathrm{N}$ & $\mathrm{Y}$ & $\mathrm{N}$ & $\mathrm{Y}$ & $\mathrm{N}$ \\
\hline 3 & 14 & 1 & IMN & $\mathrm{B} 1$ & Q & 4 & 7 & $\mathrm{~N}$ & $0^{\circ}$ & $\mathrm{Y}$ & $\mathrm{N}$ & $\mathrm{N}$ & $\mathrm{N}$ & $\mathrm{N}$ & $\mathrm{Y}$ & $\mathrm{N}$ \\
\hline 4 & 11 & $3 \mathrm{~A}$ & $\mathrm{EF}$ & $\mathrm{B} 1$ & Q & 6 & 10.5 & $\mathrm{~N}$ & $3^{\circ}$ & $\mathrm{Y}$ & $\mathrm{N}$ & $\mathrm{N}$ & $\mathrm{N}$ & $\mathrm{N}$ & $\mathrm{Y}$ & $\mathrm{N}$ \\
\hline 5 & 10.5 & 1 & $\mathrm{CW}$ & B1 & Q & 7 & 10 & $\mathrm{~N}$ & $3^{\circ}$ & $\mathrm{Y}$ & $\mathrm{N}$ & $\mathrm{N}$ & $\mathrm{N}$ & $\mathrm{N}$ & $\mathrm{Y}$ & $\mathrm{N}$ \\
\hline 6 & 12.5 & $3 \mathrm{~B}$ & $\mathrm{EF}$ & B3 & A & 12 & 16 & $\mathrm{~N}$ & $9^{\circ}$ & $\mathrm{Y}$ & $\mathrm{Y}$ & $\mathrm{N}$ & $\mathrm{Y}$ & $\mathrm{N}$ & $\mathrm{Y}$ & $\mathrm{Y}$ \\
\hline 7 & 10.5 & $3 \mathrm{~B}$ & $\mathrm{EF}$ & B3 & Q & 6.7 & 9.5 & $\mathrm{~N}$ & $5^{\circ}$ & $\mathrm{Y}$ & $\mathrm{N}$ & $\mathrm{N}$ & $\mathrm{N}$ & $\mathrm{N}$ & $\mathrm{Y}$ & $\mathrm{Y}$ \\
\hline 8 & 11.5 & $3 \mathrm{~B}$ & $\mathrm{EF}$ & B3 & A & 7.5 & 10 & $\mathrm{~N}$ & $5^{\circ}$ & $\mathrm{Y}$ & $\mathrm{N}$ & $\mathrm{N}$ & $\mathrm{N}$ & $\mathrm{N}$ & $\mathrm{Y}$ & $\mathrm{N}$ \\
\hline 9 & 10 & $3 \mathrm{~A}$ & $\mathrm{EF}$ & B1 & Q & 4.7 & 8 & $\mathrm{~N}$ & $0^{\circ}$ & $\mathrm{Y}$ & $\mathrm{N}$ & $\mathrm{N}$ & $\mathrm{N}$ & $\mathrm{N}$ & $\mathrm{Y}$ & $\mathrm{N}$ \\
\hline 10 & 13.5 & $3 \mathrm{~B}$ & $\mathrm{EF}$ & B3 & Q & 8 & 11.5 & $\mathrm{~N}$ & $5^{\circ}$ & $\mathrm{Y}$ & $\mathrm{N}$ & $\mathrm{N}$ & $\mathrm{N}$ & $\mathrm{N}$ & $\mathrm{Y}$ & $\mathrm{Y}$ \\
\hline 11 & 9 & $3 \mathrm{~B}$ & $\mathrm{EF}$ & B3 & A & 7 & 9.75 & $\mathrm{~N}$ & $4^{\circ}$ & $\mathrm{Y}$ & $\mathrm{N}$ & $\mathrm{N}$ & $\mathrm{N}$ & $\mathrm{N}$ & $\mathrm{Y}$ & $\mathrm{Y}$ \\
\hline 12 & 9 & 1 & IMN & B1 & $\mathrm{Q}$ & 4.3 & 7 & $\mathrm{~N}$ & $0^{\circ}$ & $\mathrm{Y}$ & $\mathrm{N}$ & $\mathrm{N}$ & $\mathrm{N}$ & $\mathrm{N}$ & $\mathrm{Y}$ & $\mathrm{N}$ \\
\hline 13 & 9.5 & $3 \mathrm{~B}$ & $\mathrm{EF}$ & B3 & Q & 8.4 & 10.5 & $\mathrm{~N}$ & $4^{\circ}$ & $\mathrm{Y}$ & $\mathrm{Y}$ & $\mathrm{N}$ & $\mathrm{Y}$ & $\mathrm{N}$ & $\mathrm{Y}$ & $\mathrm{N}$ \\
\hline 14 & 10.5 & $3 \mathrm{~B}$ & $\mathrm{EF}$ & B3 & A & 9 & 11.5 & $\mathrm{~N}$ & $6^{\circ}$ & $\mathrm{Y}$ & $\mathrm{N}$ & $\mathrm{N}$ & $\mathrm{N}$ & $\mathrm{N}$ & $\mathrm{Y}$ & $\mathrm{Y}$ \\
\hline 15 & 9.5 & $3 \mathrm{~A}$ & $\mathrm{EF}$ & B1 & $\mathrm{Q}$ & 4 & 7.75 & $\mathrm{~N}$ & $0^{\circ}$ & $\mathrm{Y}$ & $\mathrm{N}$ & $\mathrm{N}$ & $\mathrm{N}$ & $\mathrm{N}$ & $\mathrm{Y}$ & $\mathrm{N}$ \\
\hline 16 & 9.5 & 2 & IMN & B1 & $\mathrm{Q}$ & 4.5 & 7.5 & $\mathrm{~N}$ & $0^{\circ}$ & $\mathrm{Y}$ & $\mathrm{N}$ & $\mathrm{N}$ & $\mathrm{N}$ & $\mathrm{N}$ & $\mathrm{Y}$ & $\mathrm{N}$ \\
\hline 17 & 11.5 & $3 B$ & $\mathrm{EF}$ & B3 & Q & 7 & 9.25 & $\mathrm{~N}$ & $4^{\circ}$ & $\mathrm{Y}$ & $\mathrm{N}$ & $\mathrm{N}$ & $\mathrm{N}$ & $\mathrm{N}$ & $\mathrm{Y}$ & $\mathrm{Y}$ \\
\hline 18 & 12.5 & $3 \mathrm{~A}$ & $\mathrm{EF}$ & B1 & A & 4 & 6.5 & $\mathrm{~N}$ & $0^{\circ}$ & $\mathrm{Y}$ & $\mathrm{N}$ & $\mathrm{N}$ & $\mathrm{N}$ & $\mathrm{N}$ & $\mathrm{Y}$ & $\mathrm{N}$ \\
\hline 19 & 10 & 1 & $\mathrm{CW}$ & B3 & $\mathrm{Q}$ & 4.2 & 7 & $\mathrm{~N}$ & $0^{\circ}$ & $\mathrm{Y}$ & $\mathrm{N}$ & $\mathrm{N}$ & $\mathrm{N}$ & $\mathrm{N}$ & $\mathrm{Y}$ & $\mathrm{N}$ \\
\hline 20 & 10 & 2 & IMN & B1 & Q & 4.4 & 8 & $\mathrm{~N}$ & $0^{\circ}$ & $\mathrm{Y}$ & $\mathrm{N}$ & $\mathrm{N}$ & $\mathrm{N}$ & $\mathrm{N}$ & $\mathrm{Y}$ & $\mathrm{N}$ \\
\hline 21 & 9.5 & $3 \mathrm{~B}$ & $\mathrm{EF}$ & B3 & A & 11 & 14.5 & $\mathrm{~N}$ & $9^{\circ}$ & $\mathrm{Y}$ & $\mathrm{Y}$ & $\mathrm{Y}$ & $\mathrm{Y}$ & $\mathrm{N}$ & $\mathrm{Y}$ & $\mathrm{Y}$ \\
\hline 22 & 10 & $3 \mathrm{~A}$ & $\mathrm{EF}$ & B3 & A & 4.5 & 7.75 & $\mathrm{~N}$ & $2^{\circ}$ & $\mathrm{Y}$ & $\mathrm{N}$ & $\mathrm{N}$ & $\mathrm{N}$ & $\mathrm{N}$ & $\mathrm{Y}$ & $\mathrm{N}$ \\
\hline 23 & 9 & 1 & IMN & B1 & Q & 4.3 & 8 & $\mathrm{~N}$ & $0^{\circ}$ & $\mathrm{Y}$ & $\mathrm{N}$ & $\mathrm{N}$ & $\mathrm{N}$ & $\mathrm{N}$ & $\mathrm{Y}$ & $\mathrm{N}$ \\
\hline 24 & 10.5 & $3 \mathrm{~B}$ & $\mathrm{EF}$ & B3 & A & 8.5 & 10.5 & $\mathrm{~N}$ & $5^{\circ}$ & $\mathrm{Y}$ & $\mathrm{N}$ & $\mathrm{N}$ & $\mathrm{N}$ & $\mathrm{N}$ & $\mathrm{Y}$ & $\mathrm{Y}$ \\
\hline 25 & 11.5 & $3 \mathrm{~A}$ & $\mathrm{EF}$ & B3 & A & 5.5 & 8.25 & $\mathrm{~N}$ & $3^{\circ}$ & $\mathrm{Y}$ & $\mathrm{N}$ & $\mathrm{N}$ & $\mathrm{N}$ & $\mathrm{N}$ & $\mathrm{Y}$ & $\mathrm{N}$ \\
\hline
\end{tabular}

Legend: Type — Initial type of fracture, Initial man — Initial management, Classify—Non-union according to Dror Paley’s classification, Grade — Grade of open fracture according to Gustillo-Anderson classification, UT-Union time, PI-Persistent infection, D - Deformity, LLD - Limb length discrepancy < 2.5 cm, EQ/FFD - Equinus deformity or fixed flexion deformity of knee, RSD - Reflex sympathetic dystrophy, ADL - Activities of daily living and return to employment, EF-Tubular external fixator, IMN — Intramedullary nailing, CW-Above knee POP cast with window, A-Active infection, Q- Quiescent infection, $\mathrm{Y}-\mathrm{Yes}, \mathrm{N}-\mathrm{No}$.

port using the principles of distraction osteogenesis offers a solution to this complex problem. The ring fixator with tensioned wires offers rigid fixation [7] and the corticotomy contributes to the biological process of fracture healing [8]. It improves the vascular supply and thus reduces infection. Shortening and deformity associated with the gap is also effectively managed with the ring fixator.

Healing time is shortened in tibial fractures when the method of fixation allows intermittent cyclical axial loading [9]. This maintains bone mass and enhances remodeling [10]. Bone transport is done at the rate of 1 $\mathrm{mm} /$ day to bring the bone segments into maximal compression indicated by the appearance of pain. The com- pression rate is then slowed down to $1 \mathrm{~mm} / 12$ days [4]. The rationale behind this protocol is that further compression at the same rate would cause intense pain and bending of the wires in the construct. Bone grafting was not done in any case, in contrast to other series in literature where the rate of bone grafting ranged from $10 \%$ to $72.22 \%$ [11-14]. The mean time taken for union from the time of application of ring fixator, 11.12 months, is comparable with other series in literature which ranged from 13.6 to 16.7 months $[3,15]$. This duration correlates well with the quantum of bone gap. The time taken for union, per centimeter of bone gap in our series $(1.7$ months $/ \mathrm{cm})$ is better than the series of Bobroff et al. (2 months $/ \mathrm{cm}$ ) [15]. The success rate of our series is comparable to other 


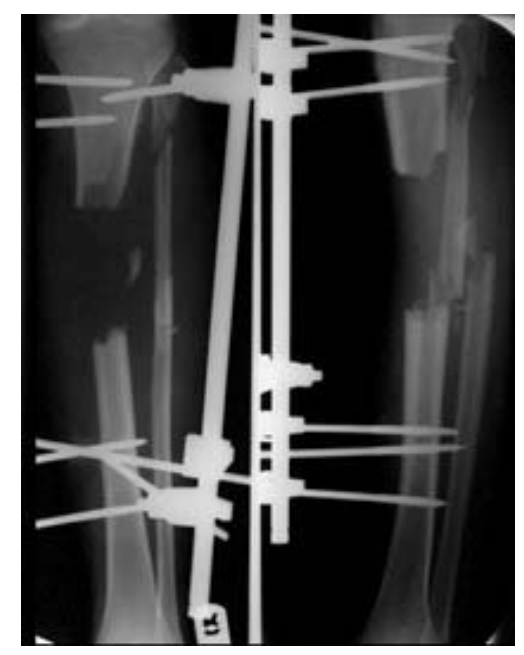

Figure 1. Gap non-union.

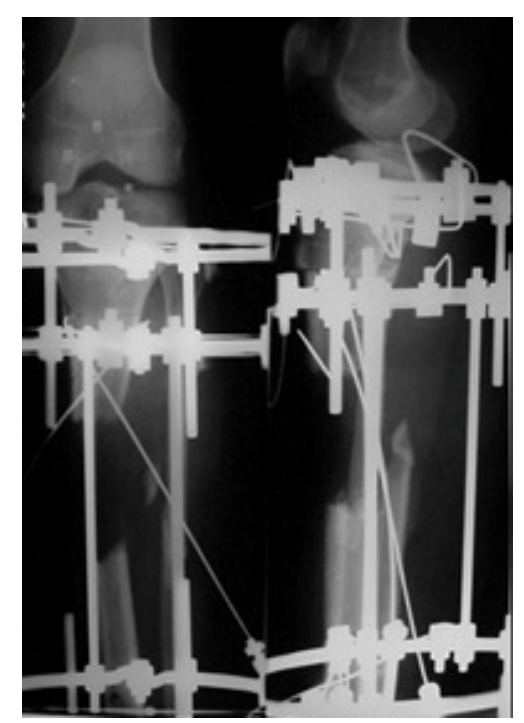

Figure 2. Ring fixator applied.

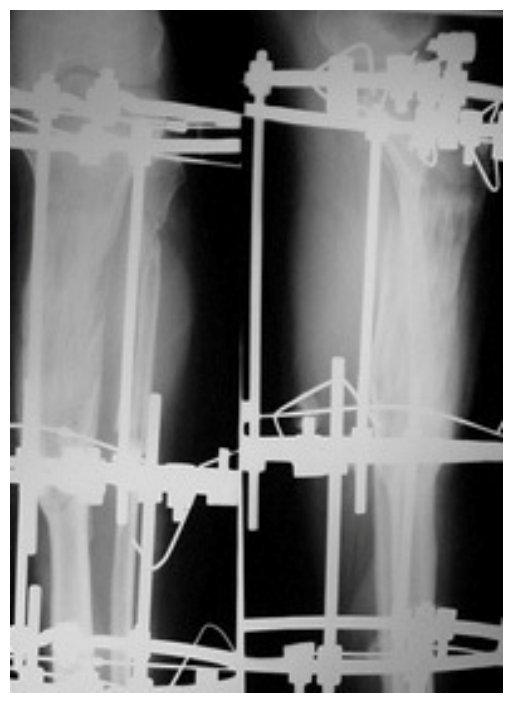

Figure 3. Regenerate in gap.

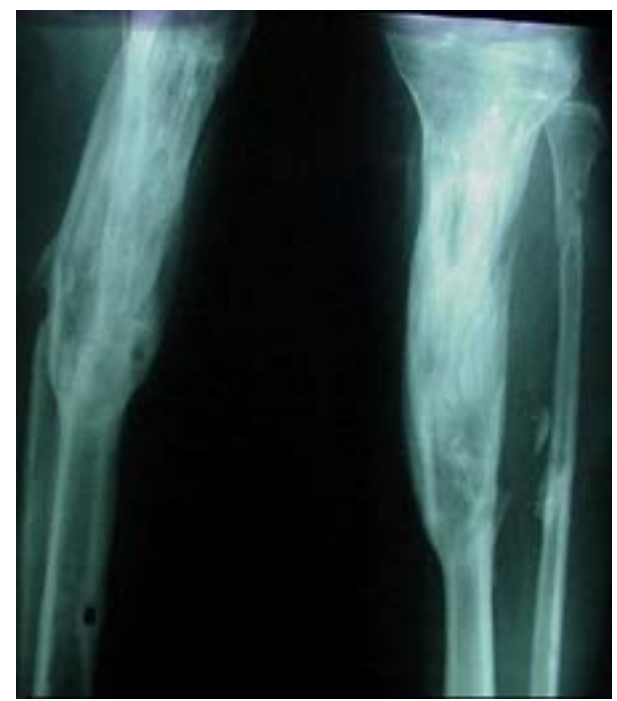

Figure 4. Union.

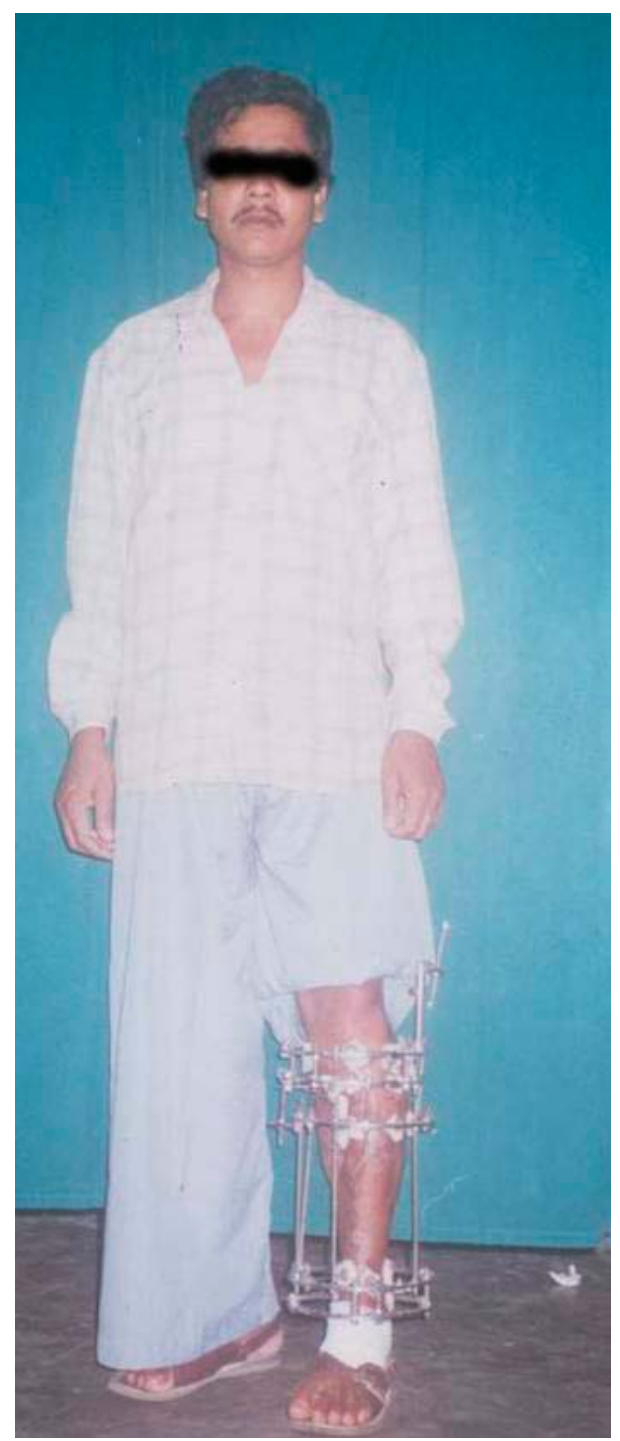

Figure 5. Fixator in situ. 


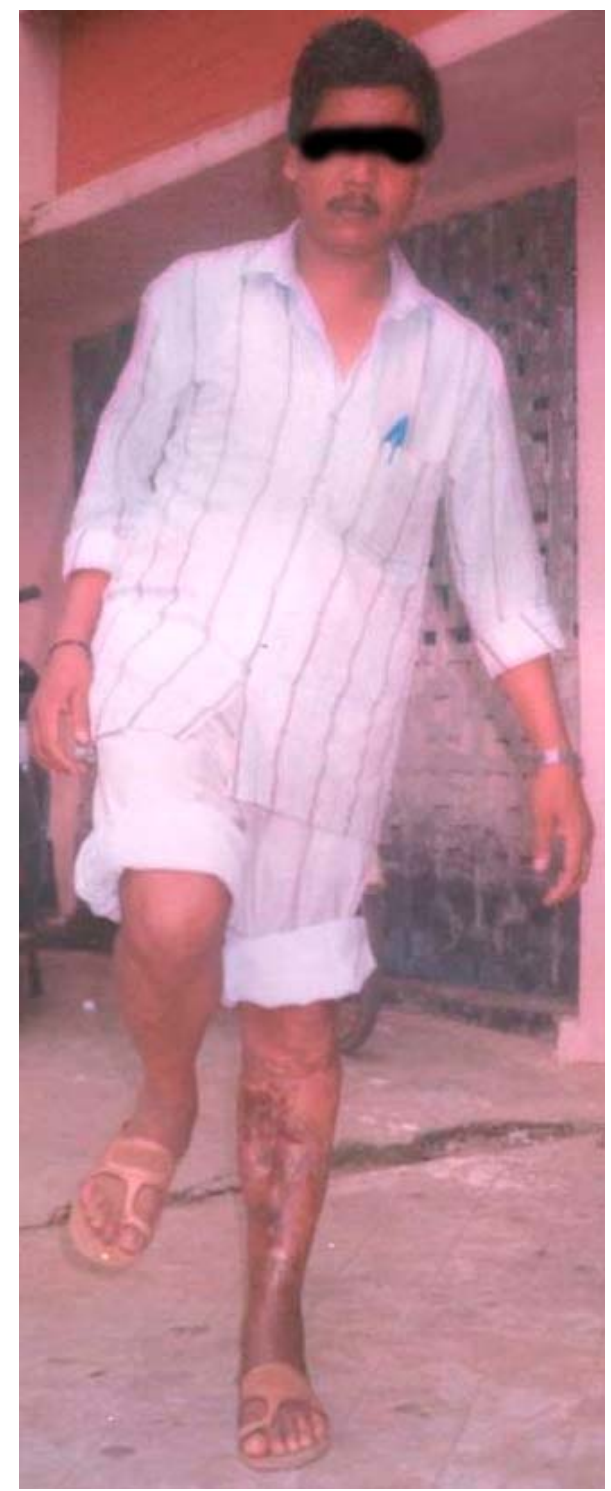

Figure 6. Full weight bearing.

series which ranged from $83 \%$ to $100 \%$ [6,14-16]. Pin tract infection was the most common complication in our series, as in other series in literature [14,16,17]. Other complications like persistence of infection [13], refracture $[11,14,18]$ and vascular injury were not encountered. The bone healing and functional results (excellent in $92 \%$ and $84 \%$ respectively) achieved also compared well with other series $[3,5,19]$.

\section{Conclusion}

The bone transport technique introduced by Ilizarov regenerates bone in the gap along with lengthening, correction of deformity, increase in local vascularity and eradication of infection. The procedure gives good to excellent bone healing and functional results. It offers a comprehensive approach to management of such difficult ca- ses, making it a technique par excellence in the treatment of gap non-union of the tibia.

\section{REFERENCES}

[1] A. Paige Whittle, "Fractures of the Lower Extremity," In: S. Terry Canale and H. B. James, Eds., Campbell's Operative Orthopaedics, Mosby, Philadelphia, 2008, pp. 3117-3146.

[2] D. Paley and D. C. Maar, "Ilizarov Bone Transport Treatment for Tibial Defects," Journal of Orthopaedic Trauma, 2000, Vol. 14, No. 2, pp. 76-85. doi:10.1097/00005131-200002000-00002

[3] D. Paley, M. A. Catagni, F. Argnani, A. Villa, G. B. Benedetti and R. Cattaneo, "Ilizarov Treatment of Tibial Nonunions with Bone Loss," Clinical Orthopaedics and Related Research, Vol. 241, 1989, pp. 146-165.

[4] M. Kiran and R. Jee, "Ilizarov's Method for Treatment of Nonunion of Diaphyseal Fractures of the Humerus," Indian Journal of Orthopaedics, Vol. 44, No. 4, 2010, pp. 444-447. doi:10.4103/0019-5413.69319

[5] A. Farmanullah, M. S. Khan and S. M. Awais, "Evaluation of Management of Tibial Non-Union Defect with Ilizarov Fixator," The Journal of Ayub Medical College Abbottabad, Vol. 19, No. 3, 2007, pp. 14-17.

[6] A. S. Atesalp, M. Basbozkurt, K. Erler, A. Sehirlionğlu, S. Tunay, C. Solakoğlu and E. Gür, "Treatment of Tibial Bone Defects with the Ilizarov Circular External Fixator in High Velocity Gunshot Wounds," International Orthopaedics, Vol. 22, No. 6, 1998, pp. 343-347. doi:10.1007/s002640050274

[7] B. Fleming, D. Paley, T. Kristianson and M. Pope, "A Biomechanical Analysis of the Ilizarov External Fixator," Clinical Orthopaedics and Related Research, Vol. 241, 1989, pp. 241-295.

[8] J. Aronson, B. H. Harrison, B. S. Stewart and J. H Harp, "The Histology of Distraction Osteogenesis Using Different External Fixators," Clinical Orthopaedics and Related Research, Vol. 241, 1989, pp. 106-116.

[9] A. E. Goodship and J. Kenwright, "The Influence of Induced Micromotion upon the Healing of Experimental Tibial Fractures," Journal of Bone and Joint Surgery, Vol. 67, No. 4, 1985, pp. 650-655.

[10] L. E. Lanyon and C. T. Rubin, "Static versus Dynamic Loads as an Influence on Bone Remodeling," Journal of Biomechanics, Vol. 17, No. 12, 1984, pp. 897-907. doi:10.1016/0021-9290(84)90003-4

[11] G. K. Dendrinos, S. Kontos and E. Lyritsis, "Use of the Ilizarov Technique for Treatment of Non-Union of the Tibia Associated with Infection," Journal of Bone and Joint Surgery, Vol. 77, No. 6, 1995, pp. 835-846. doi:10.1097/01.blo.0000152369.99312.c5

[12] S. Babhulkar, K. Pande and S. Babhulkar, "Non-union of the Diaphysis of Long Bones," Clinical Orthopaedics and Related Research, Vol. 431, 2005, pp. 50-56.

[13] L. Maini, M. Chadha, J. Vishwanath, S. Kapoor, A. Mehtani and B. K. Dhaon, "The Ilizarov Method in Infected Nonunion of Fractures," Injury, Vol. 31, No. 7, 2000, pp. 
509-517. doi:10.1016/S0020-1383(00)00036-X

[14] A. P. Mehtab, M. A. Siddiqui and Y. H. Soomro, "Management of Infected Non-Union Tibia with Intercalary Bone Transport," Pakistan Journal of Surgery, Vol. 24, No. 1, 2008, pp. 26-30.

[15] G. D. Bobroff, S. Gold and D. Zinar, "Ten Year Experience with Use of Ilizarov Bone Transport for Tibial Defects," Bulletin of the Hospital for Joint Diseases, Vol. 61, No. 3-4, 2003, pp. 101-107.

[16] S. A. Green, J. M. Jackson, D. M. Wall, H. Marinow and J. Ishkanian, "Management of Segmental Defects by the Ilizarov Intercalary Bone Transport Method," Clinical Orthopaedics and Related Research, Vol. 280, 1992, pp. 136-142.
[17] A. M. Abdel-Aal, "Ilizarov Bone Transport for Massive tibial Bone Defects," Orthopedics, Vol. 29, No. 1, 2006, pp. 70-74.

[18] L. Naggar, F. Chevalley, C. H. Blanc and J. J. Livio, "Treatment of Large Bone Defects with the Ilizarov Technique," Journal of trauma, Vol. 34, No. 3, 1993, pp. 390393. doi:10.1097/00005373-199303000-00014

[19] R. M. Thayur, R. Balasundaram, K. S. Manjunath, H. M. Shah, D. C. Sundaresh and N. Krishnappa, "Outcomes of Ilizarov Ring Fixation in Recalcitrant Infected Tibial NonUnions-A Prospective Study," Journal of Trauma Management \& Outcomes, Vol. 2, No. 6, 2008, pp. 6-8. doi:10.1186/1752-2897-2-6 